\title{
Lentivirus Vector Gene Therapy of Apoptin: The Expression of E-Catenin in Prostate Cancer Cells
}

YUN PAN*

Pathology Department, Department of Basic Medicine, Shijiazhuang Medical College, Shijiazhuang, 050599, China

Pan et al.: Lentivirus for apoptin gene therapy

\begin{abstract}
Lentivirus vectors are effective tools for gene therapy. The cloning of apoptosis-inducing genes in the malignant cell genome has been dramatically investigated in researches. In this study, the anti-cancer effect of the vector gene expressing the apoptin gene in the cellular class derived from prostate cancer was investigated. In this experimental study, an apoptotic expressive lenticular vector was developed to transfer the apoptin gene to the prostate cancer cell line. Then using the real time quantitative polymerase chain reaction fluorescence technique, transactional doctrine and expression of the apoptin gene were evaluated, respectively. Subsequently, the anticancer effect of apoptin gene expression in the prostate cancer cell was investigated by evaluating the expression of E-cadherin. The rate of positive green fluorescent protein cells in prostate cancer cells increased by more than $80 \%$ compared with control cells that had less than $1 \%$ green fluorescent protein -positive cells expression of apoptin in cells infected with lentivirus vector-green fluorescent protein-Apoptin increased about 5-fold during $72 \mathrm{~h}(\mathrm{p}=\mathbf{0 . 0 1 7})$. Lentivirus Apoptin treated cells had higher E-cadherin expression than the control group $(p=0.013)$. The results of polymerase chain reaction showed that the lentivirus vector could affect prostate cancer cells by increasing the expression of E-cadherin gene expression in prostate cancer cells.
\end{abstract}

Key words: Gene therapy, venous lentivirus, prostate cancer, e codeine

Adherens junction connections are characteristic of epithelial and endothelial tissues. The most important role of these connections is to establish physical communication between cells which determines cell shape and maintain tissue integrity ${ }^{[1]}$. Among the proteins involved in these compounds are the supernatant proteins of the Cadherin family. Because these glycoproteins interact with cellular actin skeleton, they are involved in transmitting messages from the cell surface and altering morphology and other cellular processes $^{[2]}$. The E-cadherin protein is a member of this subfamily that is mainly expressed in epithelial tissues and is therefore one of the surface markers of epithelial cells ${ }^{[3]}$. This protein is made by the Cadherin 1 (CDH1) gene, which is made up of the long arm of chromosome 16 , which is made up of 16 exons. The protein consists of extracellular domains, a transmembrane and cytoplasmic domain. The two opposite cells between which these types of connections are made communicate with each other through the extracellular domain of their E-cadherin proteins that may be important in cancer development and metastases ${ }^{[4]}$. So far many studies have been done to inhibit metastasis of epithelial cancer cells but a drug that can inhibit metastasis haven't been identified yet. Due to its ability to induce apoptosis specifically in cancer cells apoptin has the undeniable potential to treat cancer especially in cases where chemotherapy has little response ${ }^{[5]}$. One notable feature of the apoptin gene is its specific function in inducing cell death in various cancer cells including hepatoma, osteosarcoma, melanoma, colon cancer, lung, breast, prostate, cervix and stomach while not affect induction apoptosis ${ }^{[6,7]}$. The mechanism of action of apoptin haven't been elucidated completely, but the specific induction of apoptosis has been demonstrated in some cancer cells ${ }^{[8,9]}$. The apoptin gene is isolated from the bird anemia virus. This small virus causes cytopathogenic effects on bird thymocytes by causing apoptosis. The virus genome encodes three proteins, VP3 (13.6 kDa), VP2 (24.0 kDa), and VP1 (51.6 kDa). The VP1 gene encodes the protein capsid of the virus which activates important signals for virus replication

*Address for correspondence

E-mail: panyunye2020@126.com 
VP3 also called apoptin, which alone can induce cell death in many cells ${ }^{[5]}$. Gene therapy is a new method that has received a lot of attention today due to its role in the treatment of genetic diseases and various cancers. The main purpose of this method is to transfer a specific gene to the target cell and consequently to express that gene in the cell to create therapeutic effects ${ }^{[10]}$. Today lentiviruses are used as a way to transmit genes. Lenticular viruses are one of the subtypes of retroviruses and have RNAs that have the specific ability to convert their RNA into double-stranded DNA, which can be inserted into the host cells genome. This feature has been used to create vectors with therapeutic applications. Also, viral lenticular vectors can infect a wide range of cell types while being much less toxic than other viral vectors ${ }^{[11]}$.Therefore, in this study, by inserting apoptin by lentivirus vector into prostate cancer (PC-3) cells, the effect of apoptin in inducing cell death of PC-3 cell line and on the amount of E-cadherin gene expression in PC-3 cells has been discussed. Cell category (ATCC No. CRL1435) PC-3 was purchased from the Cell Bank. Cells were cultured in 1640-RPMI culture medium containing $10 \%$ bovine serum (Invitrogen), streptomycin/penicillin antibiotic (1 \% volume). Generation and titration of lentivirus vector expressing apoptin gene: To construct lentivirus vector from three gene plasmid plasmids ( $\mathrm{pCDH}$ ), plasmid vector plasmid plasma (pMD2G) plasmid, the plasmid containing gene constituents of vector lentivirus vector 2 (psPAX) Used. The viral lenticular vector with the apoptin gene (LVGFP-Apoptin) is derived from the plasmid pCDNA3.1GFP-Apoptin by the PCR Cloning method. For this purpose, a primer was designed for apoptin inside the pCDNA plasmid, which contained two cutting sites for BamHI and ECORI enzymes on both sides. After Polymerase chain reaction (PCR), the apoptin gene electrophoresis band was extracted from the gel and then transferred to the $\mathrm{pCDH}$ plasmid. All three plasmids (pCDH, PMD2G, psAX2) were then transferred to the HEK293T cell line by PolyFect Transfection-Reagent and the virus was then removed at 48,72 and $96 \mathrm{~h}$. Ultrasound requires $3 \mathrm{~h}$ to concentrate the virus ${ }^{[12,13]}$. To titrate the concentrated virus, the amount of p24 protein was measured by a small enzyme-linked immunosorbent assay (ELISA) kit. The number of viruses was also calculated by considering all 2000 molecules of p24 for each virus. This procedure was repeated for both lentivirus vectors with apoptin gene and without apoptin gene, and in this study, was used for all tests ${ }^{[14]} .10000$ cells were added to each 96cell plate well containing LV-GFP-Apoptin and incubated for 24, 48 and $72 \mathrm{~h}$ in a $\mathrm{CO} 2$ incubator. The DMSO microliter was added to each well. The optical absorption of each well was read by the plate device Eliza reader at a wavelength of $570 \mathrm{~nm}$ and the same for control ${ }^{[15]}$. After treating the cells in two 96-well plates, $48 \mathrm{~h}$ using Trypsin-EDTA, the cells were separated from the platelets and RNA extraction was performed using RNA RNX Plus extraction kit. After measuring the concentration of extracted RNA with the nanodrop device, $2 \mu \mathrm{g}$ of RNA were used to make complementary DNA (cDNA). Using the special primers of the in-E gene, the expression of this gene in cells treated with different concentrations of pomegranate seed extract was studied. After treatment of Reh cells with lentivirus vector for $48 \mathrm{~h}$, their RNA was extracted according to the high pure RNA isolation kit (Roche) guidelines and used to produce cDNA. Reverted first-strand cDNA synthesis kit was used to synthesize cDNA. The volume required for this reaction is 20 microliters, and the contents of the above solution were incubated for $5 \mathrm{~min}$ at $65^{\circ}, 5 \mathrm{~min}$ at $25^{\circ}$ and one $\mathrm{h}$ at $42^{\circ}$. cDNA prepared at $20^{\circ}$ is stored. The Real-Time PCR (RT-PCR) test was performed on a light-cycler (Roche) device at a volume of 20 microliters. For each reaction, 10 microliters of Syber premix Ex Taq, 2 microliters of cDNA, 0.5 microliters of each primer (for E-catenin and PC-3, separately) and 7 microliters of water free of nuclease were used. The temperature conditions used include an initial activation phase at $95^{\circ}$ for $30 \mathrm{sec}$ and then 40 cycles for denaturation $(5 \mathrm{sec}$ at $\left.95^{\circ}\right)$ and combined verse/reverse $\left(20 \mathrm{sec}\right.$ at $\left.60^{\circ}\right)$. The melting curve was examined for product specificity. Finally, for the relative calculation of the number of duplicated mRNA copies, the formula 2- $\Delta \Delta$ ct was used ${ }^{[14,16,17]}$. All tests were performed in the form of three independent tests and the reported values were recorded as Mean \pm SD. Also, for statistical calculations, the T-Test method, SPSS21 software and GraphPad Prism 7 were used. $p<0.05$ was considered significant. Investigating the titration and rate of entry of the lentivirus vector into PC-3 cells, the rate of entry of Apoptin-GFP-LV into PC-3 cells was examined by fluorescent microscopy. The rate of positive GFP cells in PC-3 cells increased by more than $80 \%$ compared with control cells that had less than $1 \%$ GFP-positive cells. These results are consistent with photos taken from cells after $72 \mathrm{~h}$ of exposure to the lentivirus vector expressing the apoptin gene, and the high levels of positive GFP cells seen in green indicate the high percentage of entry of the lentivirus vector (fig. 1). Assessment of apoptin gene expression was done in 
infected cells with lentivirus. To evaluate apoptin expression after the inoculation of the lentivirus vector containing the apoptin gene into PC-3 cell, cells were collected at 24, 48 and 72 an hours and PCR-RT was performed for apoptin. The results showed that the expression of apoptin in cells infected with LV-GFPApoptin increased about 5-fold during 72 an hours based on the Friedman test ( $\mathrm{p}=0.017$, fig. 2). LV-GFPApoptin treated cells had higher E-cadherin expression than the control group ( $\mathrm{p}=0.013$, fig. 3 ).

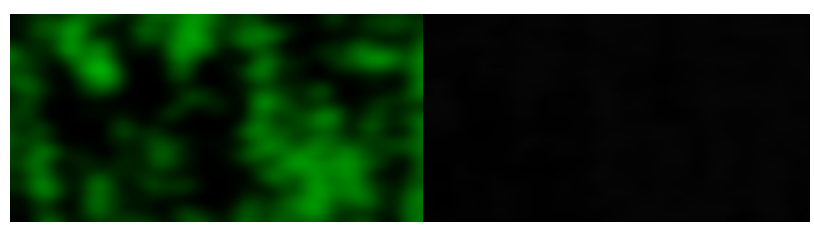

Fig 1: GFP fluorescence test; the high number of GFP-positive cells in lentivirus treated cell line

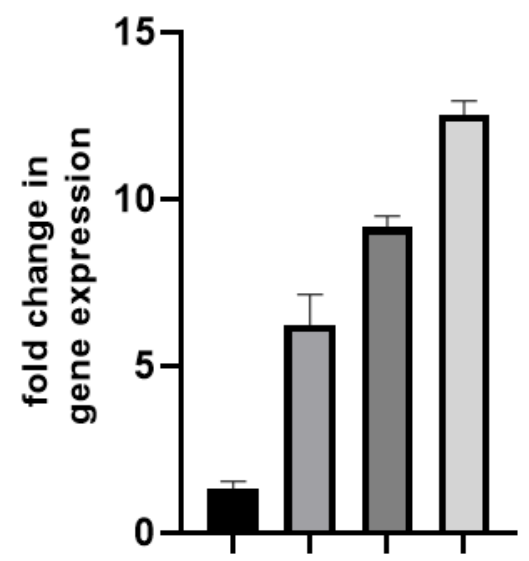

Fig 2: Expression of apoptin in LV-GFP-Apoptin infected cells, ( ) Control; (口) 24 h later; (口) 48 h later; (口) 72 h later

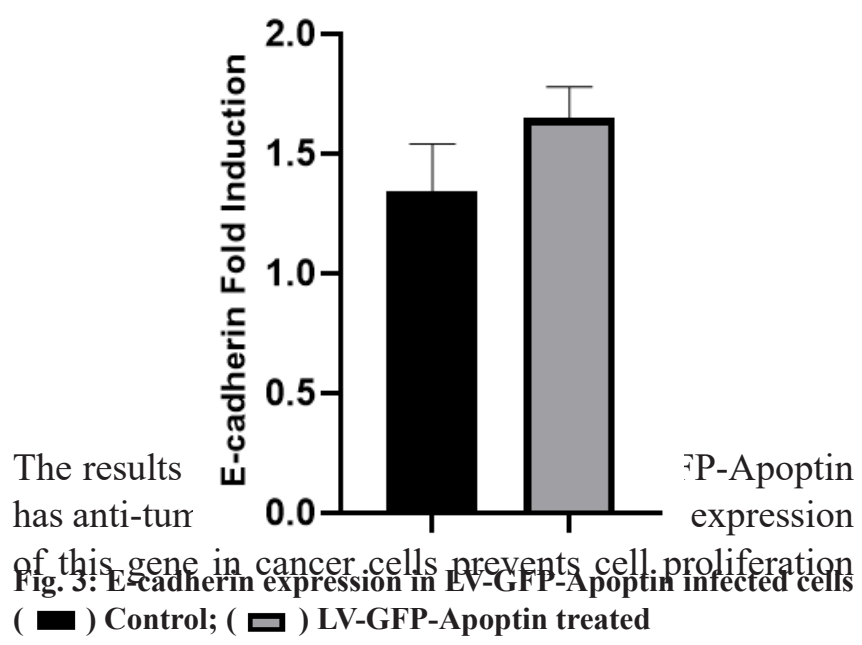

and induces cell death. There are several ways to express protein inside a cell and the use of viral lentivirus vectors is one of the best ways to transfer genes into prostate cancer cells because of the high resistance of these types of cells to other vector ${ }^{[18]}$. The results of the GFP fluorescence test show a good LV-GFP-Apoptin function in PC-3 cells. We did not find any similar study using the same target gene and cell line. Also the expression of the apoptin gene was measured by RT-PCR, and the results showed that the expression of the apoptin gene in PC-3 cells increased significantly. Previous studies have suggested a cytotoxic effect of the apoptin gene on breast and liver cancers ${ }^{[19]}$. The inhibitory effect of apoptin gene expression is not due to the viral vector itself and the expression of the GFP gene, and the lentivirus without apoptin has little effect on cell survival rate and metabolic activity ${ }^{[20]}$. In general, the results of previous research show that viral lenticular vectors are one of the most effective methods for gene transfer, and the apoptin gene is effective in inducing apoptosis in cancer cells ${ }^{[21,22]}$. Clinical and genetic studies on the pathogenesis mechanisms of apoptin on the PC-3 cell line report that the PI3K/Akt pathway is active in prostate cancer cells ${ }^{[23]}$. These studies show that the activity of this pathway not only enhances the proliferative potential of prostate cancer; it also has a significant effect on the resistance of chemotherapy drugs or radio resistance ${ }^{[24]}$. In this study, after the transfer of the apoptin gene by the lentivirus vector, the rate of expression of the E-cadherin gene increased over time. E-cadherin protein interacts with Catenin through its cytoplasmic part with $\beta$-catenin and $\gamma$-catenin family proteins, and in this way, it is associated with cellular skeleton function ${ }^{[25]}$. In addition to participating in Junction adherence cell connections, $\beta$-catenin protein is one of the components of the signaling Wnt message pathway. This transmission path begins with the binding of Wnt ligands to Frizzled receptors on the cell membrane surface ${ }^{[26]}$. Normally, the amount of catenin- $\beta$ protein in the cell is very low, and its value is controlled by a protein complex composed of APC [Adenomatous polyposis coli], CKI $\alpha$, GSK-3 $\beta$, and Axin. By activating the Wnt message transmission pathway, the $\beta$-catenin protein degradation complex is inactivated and the amount of cellular $\beta$-catenin protein increases. By destroying cellular connections, the $\beta$-catenin protein is isolated from E-cadherin and enters the cell nucleus with LEF1/TCF transcription factors, initiating the transcription of target genes. In many cancers of the epithelial tissues, CDH1 gene expression is reduced or stopped ${ }^{[27]}$. Therefore, the 
connections between the cells are weakened and the phenomenon of migration and metastasis of cancer cells begins. Decreased or no expression of E-cadherin protein in cancer cells also causes epithelialmesenchymal transition(EMT ${ }^{[28]}$. In this phenomenon, epithelial cells lose their polar and leaf morphology and take on the morphology of mesenchymal cells capable of migration. Therefore, one of the ways to inhibit metastasis of epithelial cancer cells is to induce the expression of the gene that forms the E-cadherin protein and strengthens the junction adherence to cell connections. In this study, we successfully transferred the apoptin gene by lentivirus vector, and the rate of expression of the E-cadherin gene increased over time. The results of PCR showed that the lentivirus vector could affect PC-3 cells by increasing the expression of E-cadherin gene expression in prostate cancer cells. The results of this study show that one of the best ways to transfer genes to cancer cells that are highly resistant to medications is to use a viral lentivirus vector.

\section{Conflict of Interests:}

The authors declare no conflict of interest.

\section{REFERENCES}

1. Hartsock A, Nelson WJ. Adherens and tight junctions: structure, function, and connections to the actin cytoskeleton. Biochem Biophys Acta Biomembr 2008 ;1778(3):660-9.

2. Tsukita S, Tsukita S, Nagafuchi A, Yonemura S. Molecular linkage between cadherins and actin filaments in cell-cell adherens junctions. Curr Open Cell Biol 1992;4(5):834-9.

3. Cano A, Pérez-Moreno MA, Rodrigo I, Locascio A, Blanco MJ, del Barrio MG, et al. The transcription factor snail controls epithelial-mesenchymal transitions by repressing E-cadherin expression. Nature Cell Biol 2000;2(2):76-83.

4. Al-Moundhri MS, Al-Khanbashi M, Al-Kindi M, Al-Nabhani M, Burney IA, Al-Farsi A, et al. Association of E-cadherin (CDH1) gene polymorphisms and gastric cancer risk. World J Gastroenterol 2010;16(27):3432.

5. Los M, Panigrahi S, Rashedi I, Mandal S, Stetefeld J, Essmann F. Apoptin, a tumor-selective killer. Biochem Biophys Acta 2009; 1793(8):1335-42.

6. Beckendorf C, Noteborn MH. Apoptin towards safe and efficient anticancer therapies. Adv Exp Med Biol 2014; 818:39-59.

7. Ma J-L, Han S-X, Zhao J, Zhang D, Wang L, Li YD. Systemic delivery of lentivirus-mediated secretableTAT-apoptin eradicates hepatocellular carcinoma xenografts in nude mice. Int J Oncol 2012;41(3):1013-20.

8. Zhou S, Zhang M, Zhang J, Shen H, Tangsakar E, Wang J. Mechanisms of Apoptin-induced cell death. Med Oncol 2012;29(4):2985-91.

9. Wang C, Wang W, Wang J, Zhan H, Jiang L, Yan R. Apoptin induces apoptosis in nude mice allograft model of human bladder cancer by altering multiple bladder tumor-associated gene expression profiles. Tumour Biol 2013 1;34(3):1667-78.

10. Klimatcheva E, Rosenblatt JD, Planelles V. Lentiviral vectors and gene therapy. Front Biosci 1999; 4:481-96.

11. Amado RG, Chen IS. Lentiviral vectors--the promise of gene therapy within reach? Science 1999;285(5428):674-6.

12. Tiscorina G, Singer O, Verma IM. Production and purification of lentiviral vectors. Nat Prtoc 2006 1(1):241-5.

13. Lois C, Hong EJ, Pease S, Brown EJ, Baltimore D.Germline transmission and tissue-specific expression of transgenes delivered by lentiviral vectors. Science 2002;295(5556):86872.)

14. Najmedini AA, Vahabpour R, Jalali F, Bashash D. Design of Lentiviral Vector of Apoptin and Investigating its Cytotoxic Effect on Reh Acute Lymphoblastic Leukemia Cells. J Babol Uni Med Sci 2018 20(5):48-53.

15. Zhao J, Han S-X, Ma J-L, Ying X, Liu P, Li J, et al. The role of CDK1 in apoptin-induced apoptosis in hepatocellular carcinoma cells. Oncol Rep 2013;30(1):253-9.]

16. Carlotti F, Bazuine M, Kekarainen T, Seppen J, Pognonec $\mathrm{P}$, Maassen JA, et al. Lentiviral vectors efficiently transduce quiescent mature 3T3-L1 adipocytes. Mol Ther 2004 9(2):20917.

17. Kucharski TJ, Gamache I, Gjoerup O, Teodoro JG. DNA damage response signaling triggers nuclear localization of the chicken anemia virus protein Apoptin. J Virol 2011 85(23):12638-49?

18. Iyer M, Salazar FB, Lewis X, Zhang L, Carey M, Wu L, et al. Non-invasive imaging of enhanced prostate-specific gene expression using a two-step transcriptional amplificationbased lentivirus vector. Mol Ther 2004;10(3):545-52.

19. Zhang KJ, Qian J, Wang SB, Yang Y. Targeting Gene-ViroTherapy with AFP driving Apoptin gene shows potent antitumor effect in hepatocarcinoma. J Biomed Sci 2012;19(1):20.

20. Carlotti F, Bazuine M, Kekarainen T, Seppen J, Pognonec $\mathrm{P}$, Maassen JA, et al. Lentiviral vectors efficiently transduce quiescent mature 3T3-L1 adipocytes. Mol Ther 2004;9(2):20917.

21. Guelen L, Paterson H, Gäken J, Meyers M, Farzaneh F, Tavassoli M. TAT-apoptin is efficiently delivered and induces apoptosis in cancer cells. Oncogene 2004;23(5):1153-65.

22. Wang C, Zhang Y. Apoptin gene transfer via modified wheat histone $\mathrm{H} 4$ facilitates apoptosis of human ovarian cancer cells. Cancer Bio Ther Radio Pharm 2011;26(1):121-6.

23. Pfeil K, Eder IE, Putz T, Ramoner R, Culig Z, Ueberall F, et al. Long-term androgen-ablation causes increased resistance to $\mathrm{PI} 3 \mathrm{~K} /$ Akt pathway inhibition in prostate cancer cells. Prostate 2004;58(3):259-68.

24. Chang L, Graham PH, Ni J, Hao J, Bucci J, Cozzi PJ, et al. Targeting PI3K/Akt/mTOR signaling pathway in the treatment of prostate cancer radioresistance. Crit Rev Oncol Hematol 2015;96(3):507-17.

25. Roura S, Miravet S, Piedra J, de Herreros AG, Duñach M. Regulation of E-cadherin/Catenin association by tyrosine phosphorylation. J Biol Chem 1999;274(51):36734-40.

26. He Y, Davies CM, Harrington BS, Hellmers L, Sheng Y, Broomfield A, et al. CDCP1 enhances Wnt signaling in colorectal cancer promoting nuclear localization of $\beta$-catenin and E-cadherin. Oncogene 2020;39(1):219-33.

27. Morrow KA, Das S, Meng E, Menezes ME, Bailey SK, Metge $\mathrm{BJ}$, et al. Loss of tumor suppressor Merlin results in aberrant 
activation of Wnt/ $\beta$-catenin signaling in cancer. Onco Target 2016;7(14):17991.

28. Korpal M, Lee ES, Hu G, Kang Y. The miR-200 family inhibits epithelial-mesenchymal transition and cancer cell migration by direct targeting of E-cadherin transcriptional repressors ZEB1 and ZEB2. J Biol Chem 2008;283(22):14910-4.
This is an open access article distributed under the terms of the Creative Commons Attribution-NonCommercial-ShareAlike 3.0 License, which allows others to remix, tweak, and build upon the work non-commercially, as long as the author is credited and the new creations are licensed under the identical terms

This article was originally published in a special issue,

"Trends in Therapeutic Management of Various Clinical

Conditions II" Indian J Pharm Sci 2021:83(2)Spl issue;190-194 